\title{
Microstructural Characterization of Failed Aircraft Antenna
}

\author{
Premkumar Manda, Aginaparru Sambasiva Rao, Satyapal Singh and Ashok Kumar Singh
}

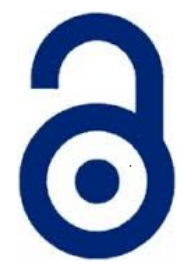

\author{
Received: 24 August 2018 \\ Accepted: 07 October 2018 \\ Published: 01 December 2018 \\ Publisher: Deer Hill Publications \\ (c) 2018 The Author(s) \\ Creative Commons: CC BY 4.0
}

\begin{abstract}
This paper presents the failure analysis of aircraft antenna which is a sub-assembly of Traffic Collision Avoidance System (TCAS) used with Air Traffic Control (ATC) transponder. The base of the damaged antenna (metallic part) is made from Al-based alloy. The micrographs exhibit the typical solidification microstructure consisting of Al-rich matrix along with $\mathrm{Si}$ - and $\mathrm{Mg}$-Si-Fe- rich phases. The antenna is coated with the paint consisting of three layers. First and third layers display the presence of $\mathrm{Ti}$ and $\mathrm{C}$ while second layer consists of $\mathrm{Si}, \mathrm{Cr}$ and $\mathrm{C}$ elements. The small amount of oxygen is also present in all the three layers. The cracks are appeared in the central region of the fin due to impact of external objects (appears to be blankings and particles). Three types of foreign object damage particles are observed on the damaged / hit area. The antenna appears to be damaged during gale as a result of hitting of the large particles lying in aircraft parking area and aircraft engine blankings.
\end{abstract}

Keywords: Aircraft antenna; Traffic collision and avoidance system; Scanning electron microscopy; Electron probe micro analyser; Fibre particles.

\section{INTRODUCTION}

The growth of airline industry has taken place exponentially during last decade. The increase in number of aircrafts has added to the risk of mid-air collision. Consequently, this has led to destruction of lives as well as massive loss of property. This has resulted in the development of advanced traffic collision and avoidance system (TCAS) by the Federal Aviation Administration (FAA), other countries' Civil Aviation Authorities (CAAs), and the aviation industry after many years of extensive research, developments and flight evaluation [1-3]. The TCAS assembly has been proposed by Morell [4].The TCAS is an assembly that provides a solution to the problem of reducing the risk of midair collision between aircrafts [1-6]. It is also known as Airborne Collision Avoidance System (ACAS) in international arena.

The TCAS assembly recognizes the presence of nearby aircraft by interrogating the transponders carried by the same. It transmits interrogations at a steady rate ( once per second) and employs a receiver to detect replies to these interrogations from the transponders on nearby aircraft. When TCAS senses a possible collision threat, it issues a traffic advisory to the pilot indicating the presence and location of the other aircraft. The TCAS suggests an action plan if the encounter becomes dangerous [2-3, 7-10]. It functions based on time criteria to issue an alert and not the distance. It calculates a time to reach the closest point of approach (CPA) with the intruder after several successive replies and by dividing the range by the closure rate. As a result, the time value becomes the main parameter for issuing alerts. It also defines the type of alert. The large and smaller values indicate high and low alerts, respectively. If the aircraft transmit their altitude, the TCAS accordingly computes the time to reach co-altitude [9-10].

The antenna, which is part of TCAS, is employed in aircraft assembly to receive and transmit signals. It can be classified as navigation and communication depending on the application. The navigation antennas are air traffic control (ATC), TCAS distance measuring equipment (DME), weather radar (WXR), global positioning system (GPS), automatic directional finder (ADF), satellite communication (SATCOM), instrument landing system (ILS), terminal wireless local area network (LAN) unit (TWLU), radio altimeter (RA) etc. While the communication antennas are very high frequency (VHF) and high frequency (HF) radios [11]. The locations of these antennas are schematically shown in Fig. 1.

P. Manda, A. S. Rao, S. Singh and A. K. Singh $\square$

Defence Metallurgical Research Laboratory

Kanchanbagh, Hyderabad, 500058, India

E-mail: singh_ashok3@rediffmail.com

Reference: Manda, P., Rao, A. S., Singh, S. and Sing, A. K. (2018). Microstructural Characterization of Failed Aircraft Antenna. International Journal of Engineering Materials and Manufacture, 3(4), 171-181. 
The TCAS assembly functions independently of ground based ATC and provide collision avoidance protection [8]. The TCAS antenna offers a directional reception of radio signals from ATC transponders of other aircraft. It is also called directional antenna. This is installed below as well as above the fuselage (Figs. 1 and 2). A sub-assembly of TCAS which is an Omni-directional antenna used with ATC transponder has been received in damaged condition. This has been employed to transmit and receive aircraft code and altitude. This component has been found in damaged condition during the daily inspection of the aircraft immediately after experiencing gale with strong surface wind. The aircraft engine blankings came off, flew and rolled on the runway during gale. Present work is thus concerned with the failure investigation of damaged aircraft antenna.

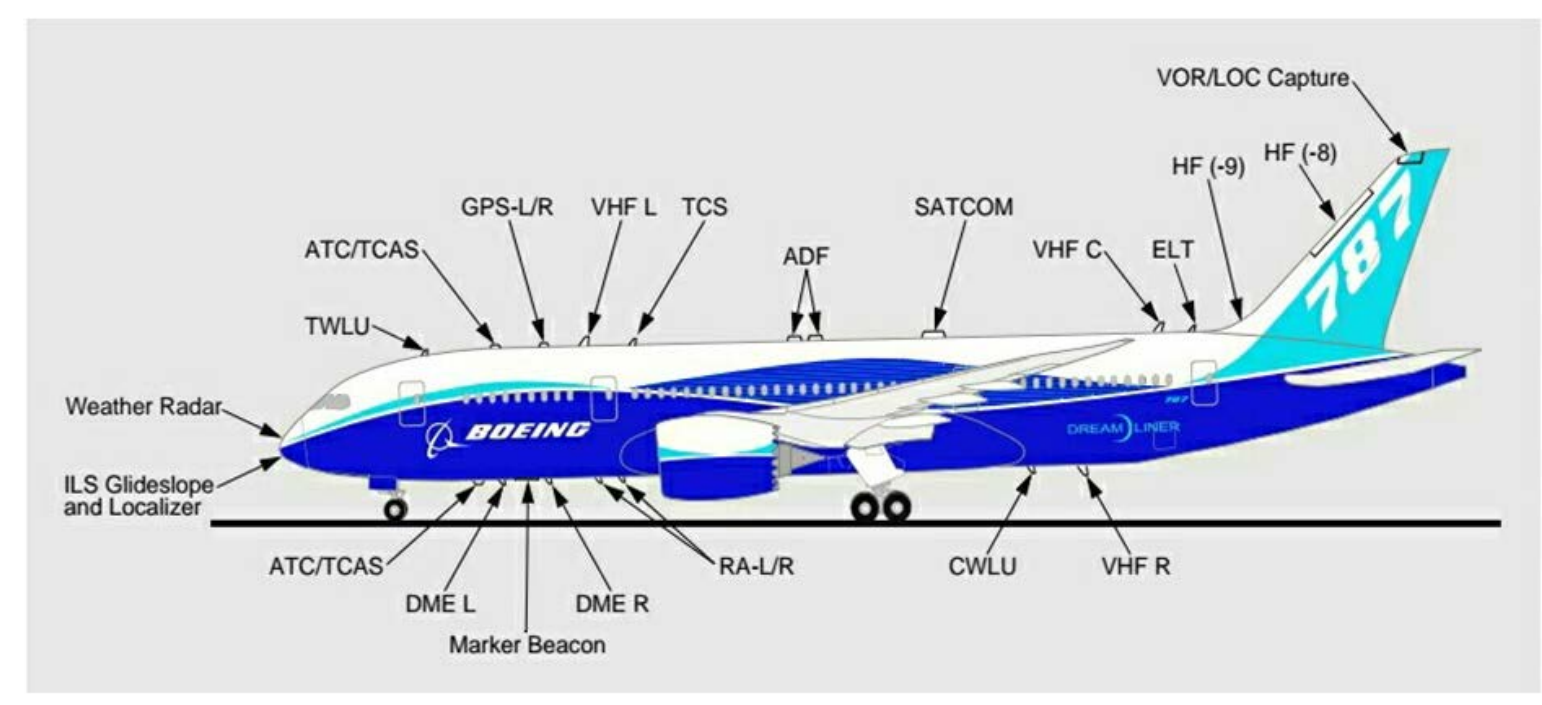

Figure 1: Typical navigation and communication antennas locations of the Boeing 787 aircraft [11].

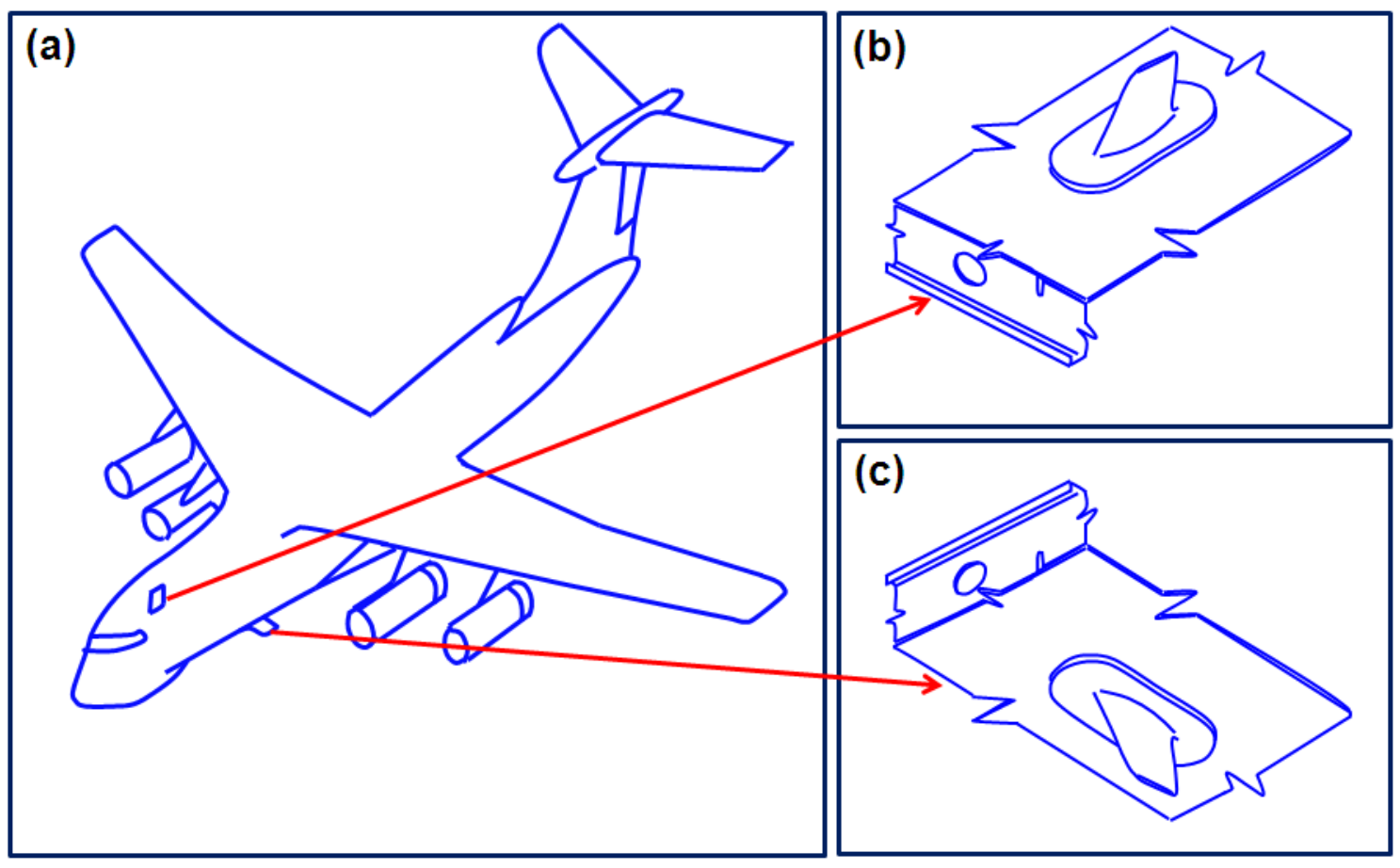

Figure 2: Schematic diagrams of: (a) aircraft; (b) top and (c) bottom antenna. 


\section{EXPERIMENTAL}

Visual examination was carried out on damaged aircraft antenna followed by photography in as-received condition. The X-ray radiography of the damaged antenna has been carried out to see the internal structure of the same (Philips: model No: MG 452 with $450 \mathrm{kV}$ ). The chemical composition of the damaged aircraft antenna was determined using Scanning Electron Microscopy (SEM: Leo 440i) and Electron Probe Micro Analyser (EPMA: SX 100 CAMECA). The Foreign Object Damage (FOD) particles were analysed using SEM. The microstructural characterization was carried out using optical microscope (OM), SEM and EPMA. Line scan profiles and X-ray mapping of elemental distribution were carried out using EPMA. The chemical composition of the metallic part of the antenna was obtained by EPMA and given in Table 1.

Table 1-Chemical composition of metallic part of damaged antenna (wt. \%).

\begin{tabular}{ccccccc}
\hline $\mathrm{Al}$ & $\mathrm{Mg}$ & $\mathrm{Si}$ & $\mathrm{Mn}$ & $\mathrm{Zn}$ & $\mathrm{Cu}$ & $\mathrm{Ti}$ \\
\hline Bal. & 0.19 & 1.15 & 0.015 & 0.03 & 0.03 & 0.26 \\
\hline
\end{tabular}

The antenna was broken to see the fracture surface of the metallic part. Fracture surface was examined in Secondary Electron (SE) mode in SEM. Energy Dispersive Spectroscopy (EDS) was employed for elemental analysis in the damaged area at different locations.

\section{RESULTS}

\subsection{Visual Examination}

The photograph of the damaged antenna in as-received condition is shown in Fig. 3. This clearly shows that the component has impact marks at the three distinct locations marked by A, B and C (Fig.3). The enlarged views of these locations are shown in Fig. 4 (a-c) corresponding to A, B and C locations (Fig. 3), respectively. It appears that a hard object has hit the antenna at these locations. As a result, paint layer has either come out (Figs. 4 (a and c)) or peeled off (Fig. 4b). The hits at points $A$ and $C$ have created dent marks. The areas near point $B$ have not displayed dents but the removal of paint layer only (Fig. 4b). There appears to be thin layer of paint applied at the base of the fin in the past during servicing.

The impact at $\mathbf{A}$ caused some damage to base of the antenna while the impact at $C$ that happened to be the tip of the fin resulted in severe cracking in the middle of the fin due to bending forces created by impact of the high velocity object. The paint of the antenna is very hard and not easily scratched or damaged. This has been tested by hammering at the base of the antenna. The removal of paint at the tip of fin in Fig. $4 \mathrm{c}$ therefore indicates that the fin has been hit by a quite hard object. This has resulted in damage observed in antenna. In addition, antenna also displays multiple cracks initiated from one end to other of the fin (Fig. 3). The high magnification photographs of these cracks are shown in Fig. 4 (d-f). These cracks are quite deep and appeared on both the side of antenna (Fig. 4 $(d-f))$.

\subsection{X-Ray Radiography}

The X-ray radiograph taken from the damaged antenna is shown in Fig. 5. The blue lines are drawn on the radiograph to understand the internal structure of the component more clearly. The cracking observed is highlighted by white rectangular box (Fig. 5). The parallel blue lines shown in the white rectangular box indicate the presence of light material due to absence of contrast in radiograph of that region.

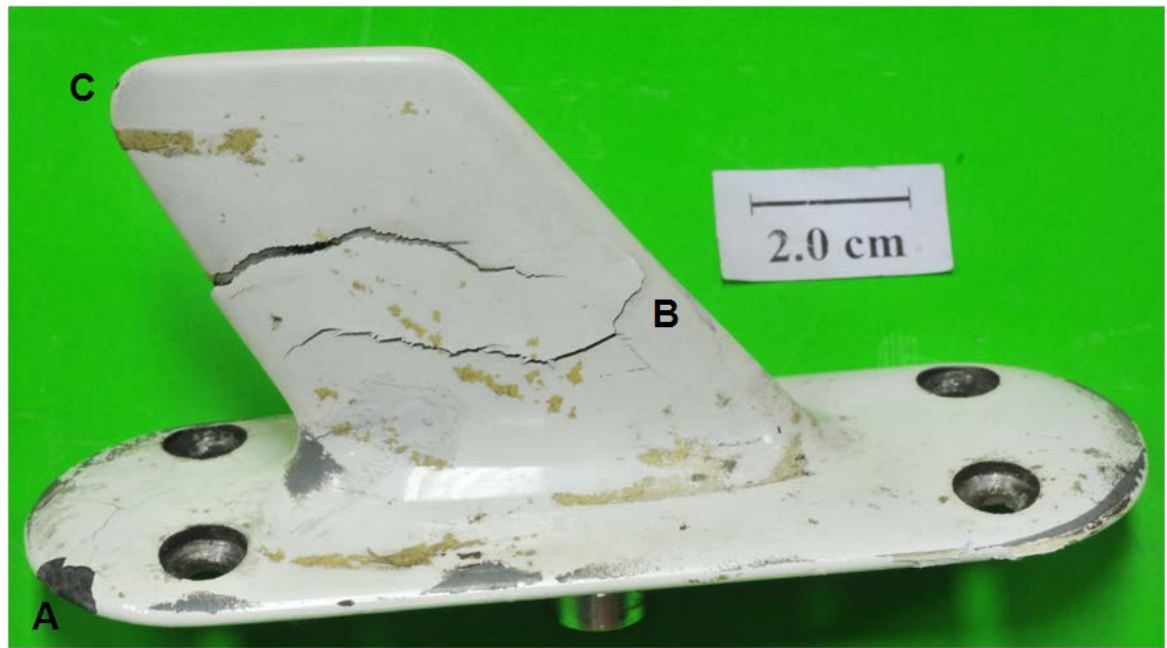

Figure 3: The photograph of the damaged antenna in as-received condition. 


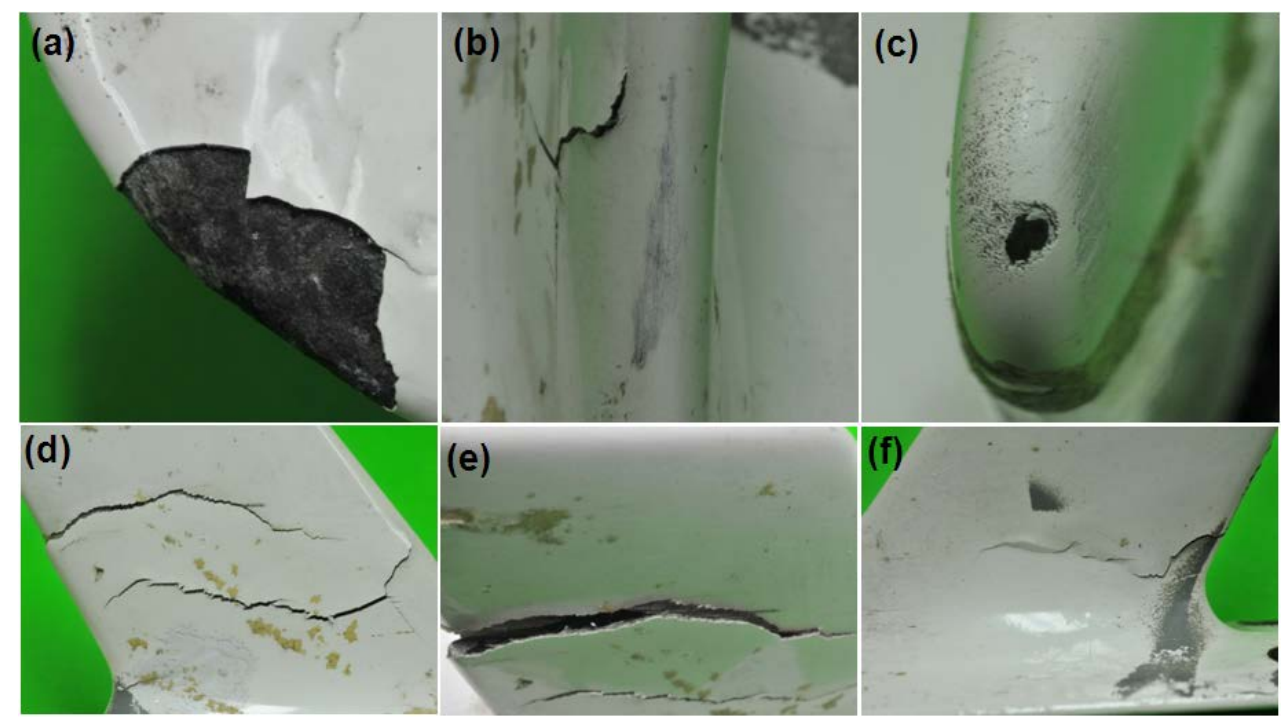

Figure 4: (a), (b) and (c) are corresponding to enlarged views of the A, B and C locations (Fig.3) displaying impact marks; (d), (e) and (f) are enlarged views of the antenna exhibiting multiple cracks at middle of the fin.

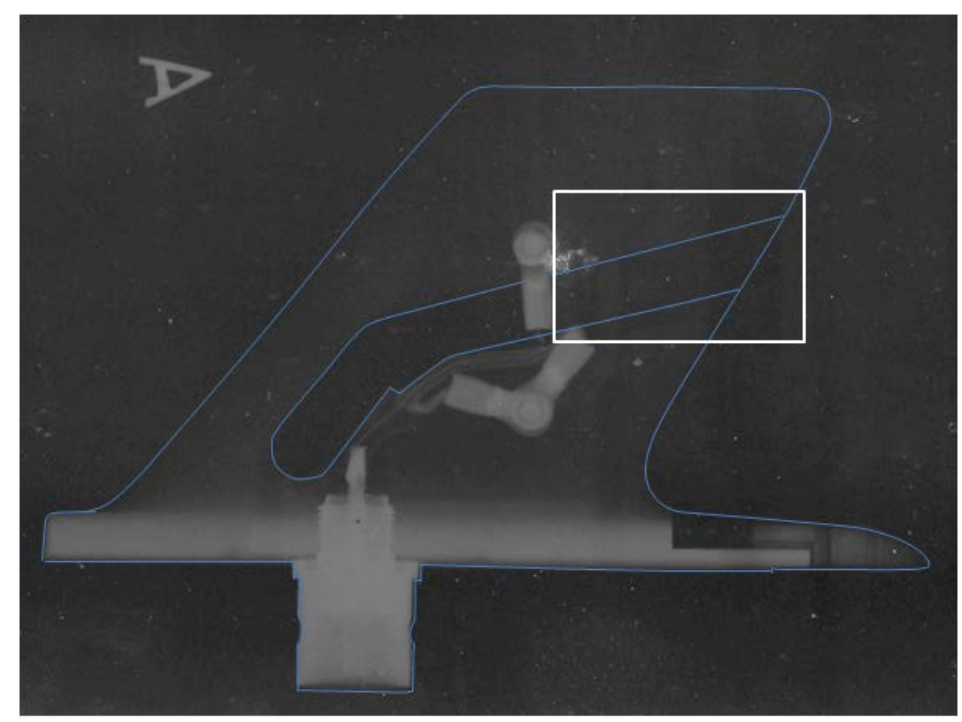

Figure 5: X-ray radiograph of the damaged antenna. Cracking area is indicated by white rectangular box.

\subsection{EDS Analysis and Fractography}

The damaged antenna is broken to see the internal structure and mode of fracture. The photographs of the broken pieces are shown in Fig. 6. These pieces are marked as $\mathrm{X}, \mathrm{Y}$ and $\mathrm{Z}$. The close view of piece marked as $\mathrm{Z}$ is displayed in Fig. 6b. The antenna consists of the three layers (top, middle and inner) as shown in Fig. 6b. The internal structure of the antenna also consists of the connecting wire (Fig. 6b).

In order to know the layers compositions, the EDS analysis has been carried out at different locations of the Fig. 6b. The EDS patterns taken from the top, middle and inner layers are shown in Fig. 7 (a-c). The top layer exhibits the presence of $\mathrm{C}, \mathrm{O}, \mathrm{Ti}, \mathrm{Fe}, \mathrm{Al}, \mathrm{Si}$ and Ti elements (Fig. 7a). This indicates the presence of the paint material. The EDS pattern of the middle layer displays the presence of $\mathrm{Al}, \mathrm{Mg}$ and $\mathrm{Si}$ (Fig. 7b). The middle layer is basically an $\mathrm{Al}$ based alloy. The inner layer exhibits the presence of $\mathrm{Si}, \mathrm{O}$ and $\mathrm{C}$ (Fig. $7 \mathrm{C}$ ). It reflects that the inner layer is made up of Si-based material.

The dent mark at location A (Fig. 3) reveals the presence of several foreign particles. These particles are marked as a, b, c, d and e on the SE SEM (Secondary Electron (SE) mode in Scanning Electron Microscopy (SEM)) images and their corresponding EDS patterns are shown in Figs. 8-12. The particle marked as a is shown in Fig. 8a and corresponding EDS pattern is exhibited in Fig. 8b. The EDS pattern reveals the presence of $\mathrm{Na}, \mathrm{O}$ and $\mathrm{Cl}$ along with 
the base material Al. The particle $b$ is shown in Fig. 9a. The corresponding EDS pattern is displayed in Fig. 9b. It exhibits the presence of $\mathrm{O}$ and $\mathrm{Si}$ indicating that the particle $\mathrm{b}$ is Si rich.
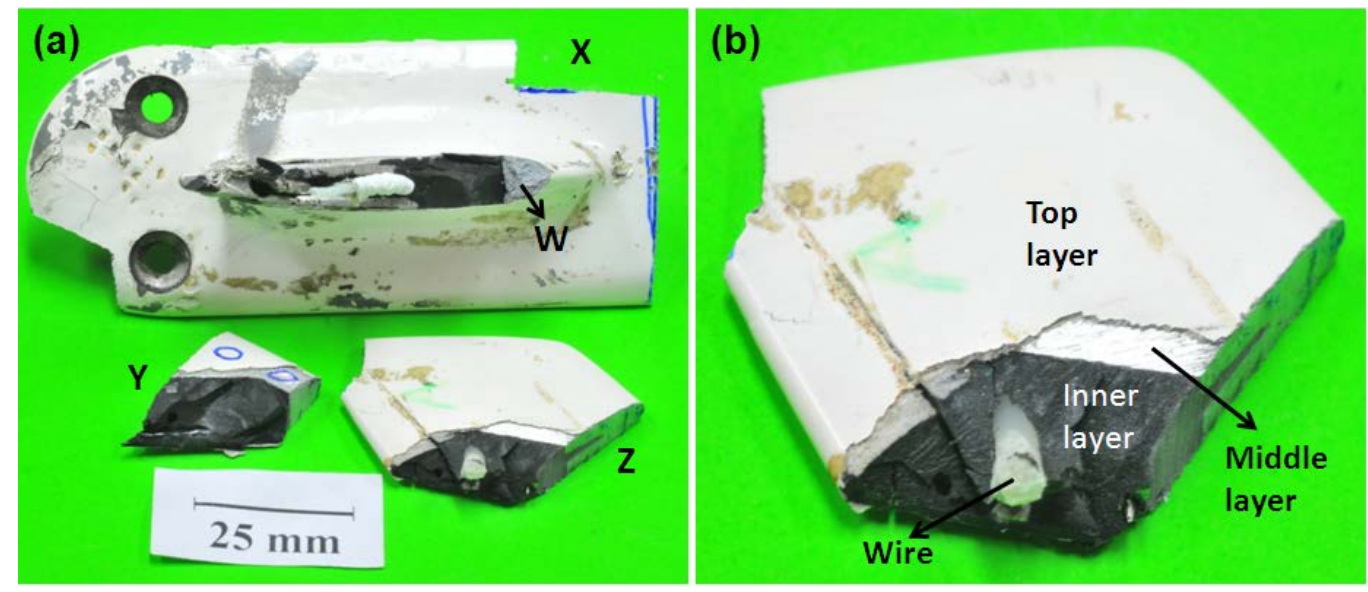

Figure 6: Broken pieces of the damaged antenna: (a) all pieces together and (b) close view of the $\mathbf{Z}$ in (a).

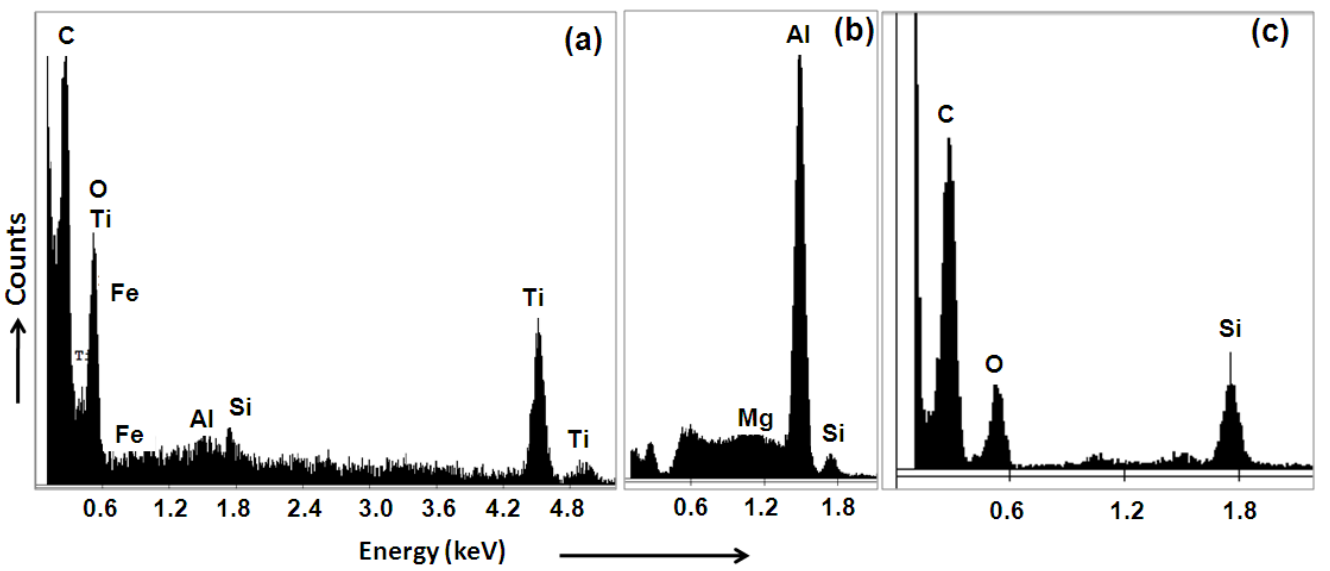

Figure 7: The EDS patterns taken from: (a) top, (b) middle and (c) inner layers of the Fig.6b.
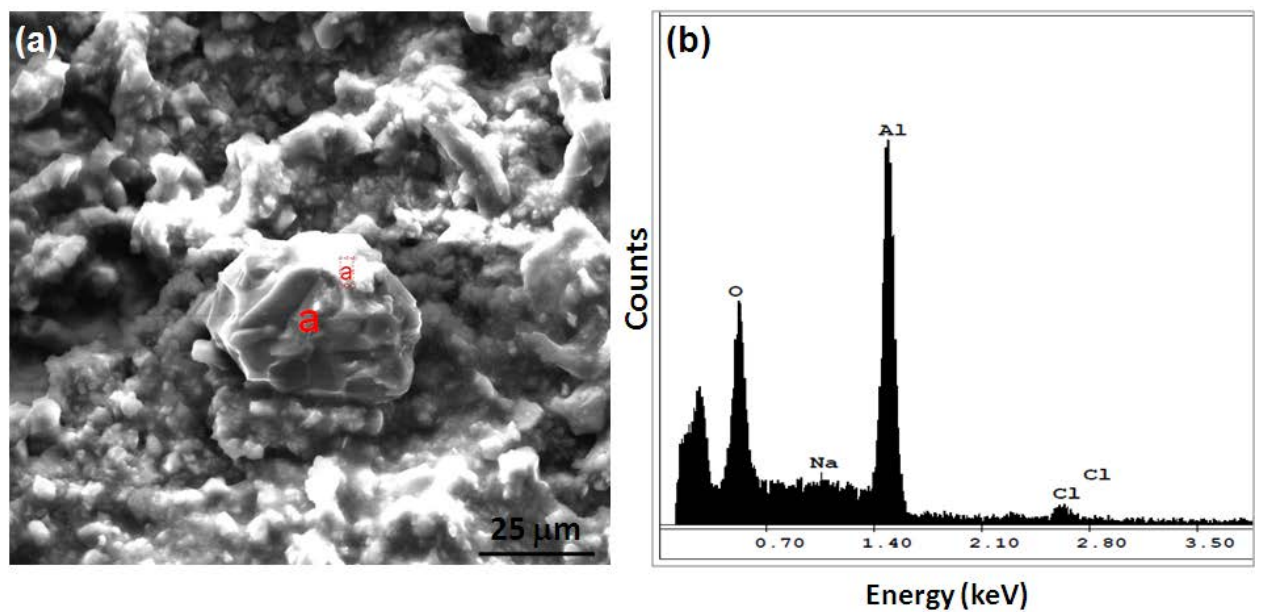

Figure 8: SE SEM image: (a) particle a in damaged portion of the antenna (location A) and (b) corresponding EDS pattern of particle $\mathbf{a}$. 
The SE SEM images showing fibre particles marked as $\mathbf{c}, \mathbf{d}$ and $\mathbf{e}$ are shown in Figs. 10-12. The fibre particle $\mathbf{c}$ (Fig.10 ( $\mathrm{a}$ and b)) exhibits the presence of $\mathrm{C}, \mathrm{O}, \mathrm{Al}, \mathrm{Si}$ and $\mathrm{Ca}$ elements. Among these, the elements $\mathrm{Al}$ is from the base material. The large amount of $\mathrm{Si}$ in this particle probably appears partly from the base as well as from particles lying on the ground (aircraft parking area). The source of $\mathrm{Ca}$ appears to be from the later particles. The fibre particle $\mathrm{d}$ (Fig. 11 (a and b)) shows the presence of $\mathrm{C}, \mathrm{O}, \mathrm{Mg}, \mathrm{Al}, \mathrm{Si}$ and Fe. As mentioned above, the presence of these elements except $\mathrm{Al}$ are due to particles lying on the ground. The fibre particle e (Fig. 12 (a and b)) displays the presence of $\mathrm{C}$, $\mathrm{O}, \mathrm{Al}, \mathrm{Si}$ and $\mathrm{S}$. The elements like $\mathrm{Mg}, \mathrm{Al}$ and $\mathrm{Si}$ form the particles $\mathbf{e}$ are from the base material.

The fracture surfaces taken from the location marked as $W$ (Fig. 6a) are shown in Fig. 13. The fracture surface exhibits the presence of two distinct features (Fig. 13b). These are marked with white and black square boxes. The high magnification images corresponding to Fig. 13b (marked with white and black square boxes) are shown in Fig. 13 ( $c$ and d). The high magnification SE SEM image taken from the white square box (Fig. 13b) is depicted in Fig. 13c. This exhibits characteristic appearance of shrinkage casting dendrites. In addition, it also displays the presence of porosity. The high magnification SE SEM image taken from the black square box (Fig. 13b) is shown in Fig. 13d. The fracture surface exhibits the presence of dimples (marked by yellow arrows in Fig. 13d) and flat facets (marked by blue arrows in Fig. 13d). The type of fracture is mixed mode.
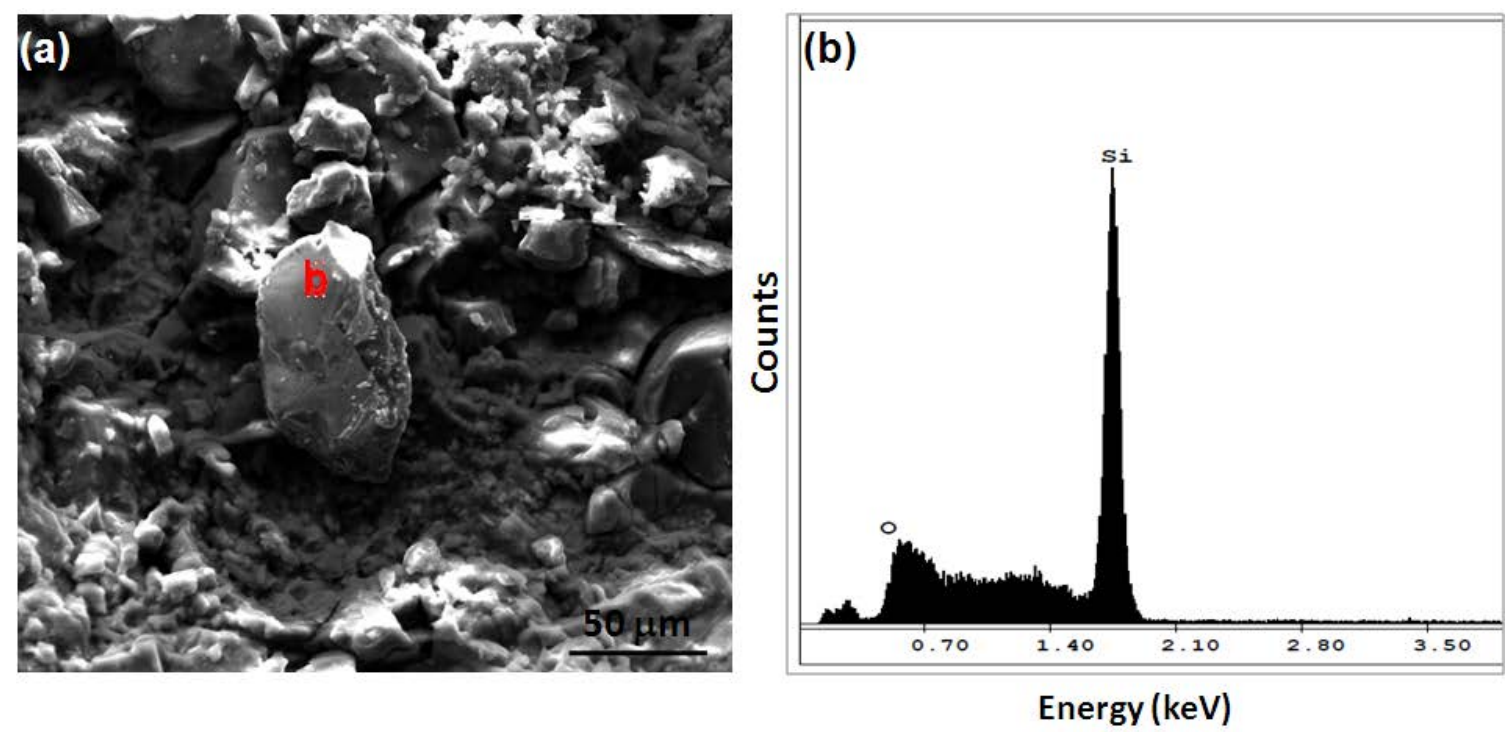

Figure 9: SE SEM image: (a) particle $b$ in damaged portion of the antenna (location $\mathbf{A}$ ) and (b) corresponding EDS pattern of article $b$.
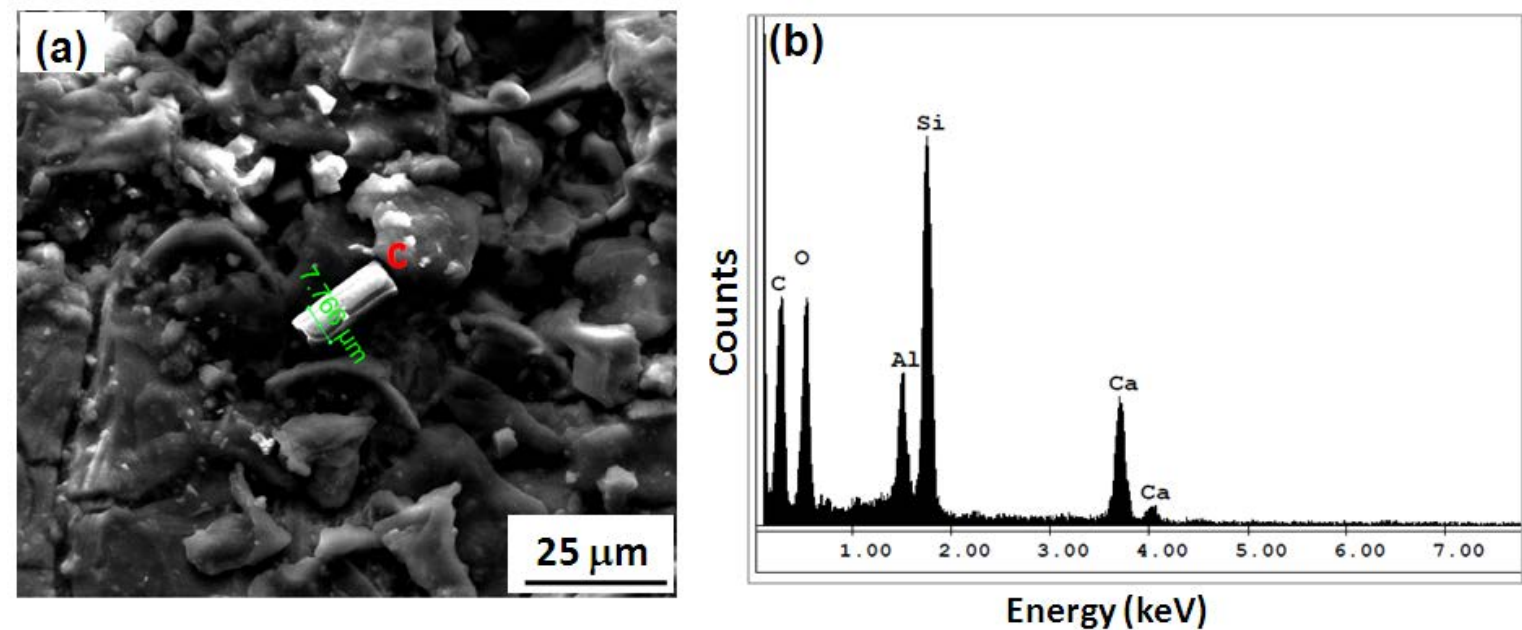

Figure 10: SE SEM image: (a) fibre particle $\mathrm{c}$ in damaged portion of the antenna (location $\mathrm{A}$ ) and (b) EDS pattern corresponding to fibre particle $\mathrm{c}$. 

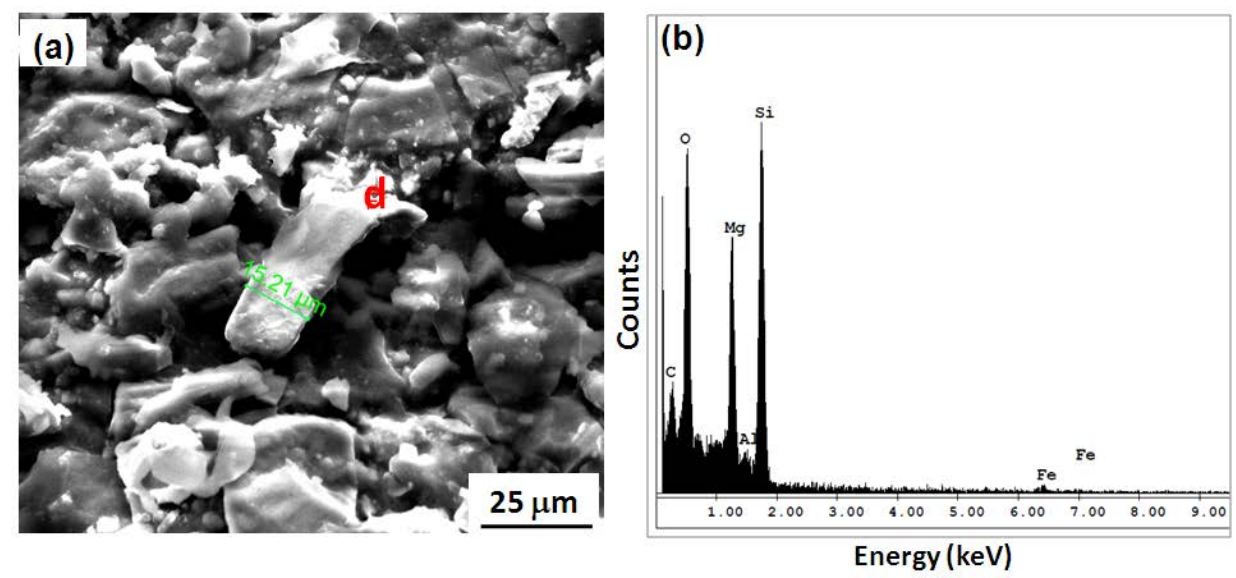

Figure 11: SE SEM image: (a) fibre particle $\mathbf{d}$ in damaged portion of the antenna (location $\mathrm{A}$ ) and (b) EDS pattern corresponding to fibre particle $\mathrm{d}$.
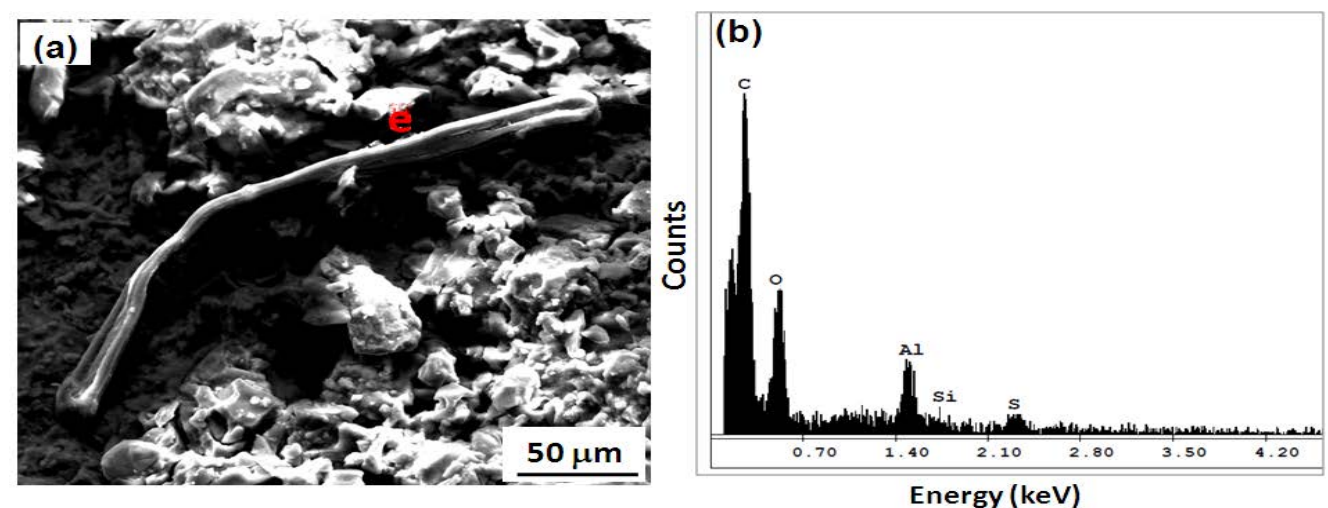

Figure 12: SE SEM image: (a) fibre particle e in damaged portion of the antenna (location A) and (b) EDS pattern corresponding to fibre particle e.

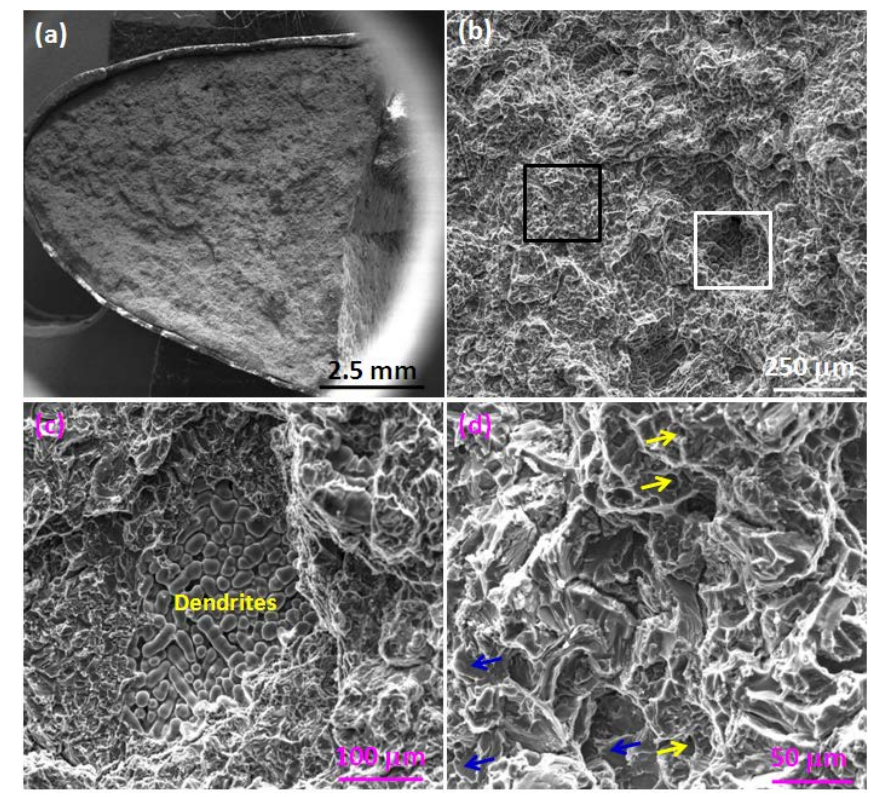

Figure 13: The fracture surfaces of the location W of the Fig. 6a: (a) low and (b) high magnifications. Different features in (b) are shown as square white and black boxes; SE SEM high magnification images of Fig. 13b corresponding to regions marked with: (c) white and (d) black square boxes. 


\subsection{Chemical Composition and Microstructure of Base of the Antenna (Metallic Part)}

The chemical composition of base of the damaged antenna (metallic part) determined from EPMA is shown in Table 1. This indicates that it is made from Al-based alloy. The optical microstructures of the as-received base of the antenna exhibit the typical solidification microstructure (Fig. 14). It displays the presence of two phases namely, primary $\alpha-\mathrm{Al}$ phase with dendrites surrounded by the eutectic Al-Si (Fig. 14 ( $a$ and b). Optical microstructure taken from the edge showing different layers of paint (Fig. 14 ( $c$ and d).

The BSE SEM (Back Scattered Electron (BSE) mode in Scanning Electron Microscopy (SEM)) microstructures taken from the cross section of base of the antenna are shown in Fig. 15. The microstructures exhibit the presence of three phases (matrix, grey and white as marked in Fig. 15b). The EPMA X-ray elemental mapping has been carried out on these phases and results are shown in Fig. 16. The distribution of $\mathrm{Al}$ is displayed in Fig. 16b. The elemental mappings of $\mathrm{Ti}, \mathrm{Fe}, \mathrm{Mg}$ and $\mathrm{Si}$ are exhibited in Fig. 16 (c-f). It is clear from the Fig. 16 that these microstructures consist of three phases. These are Al-rich matrix along with Si-rich (grey) and Mg-Si-Fe rich (white) precipitates.
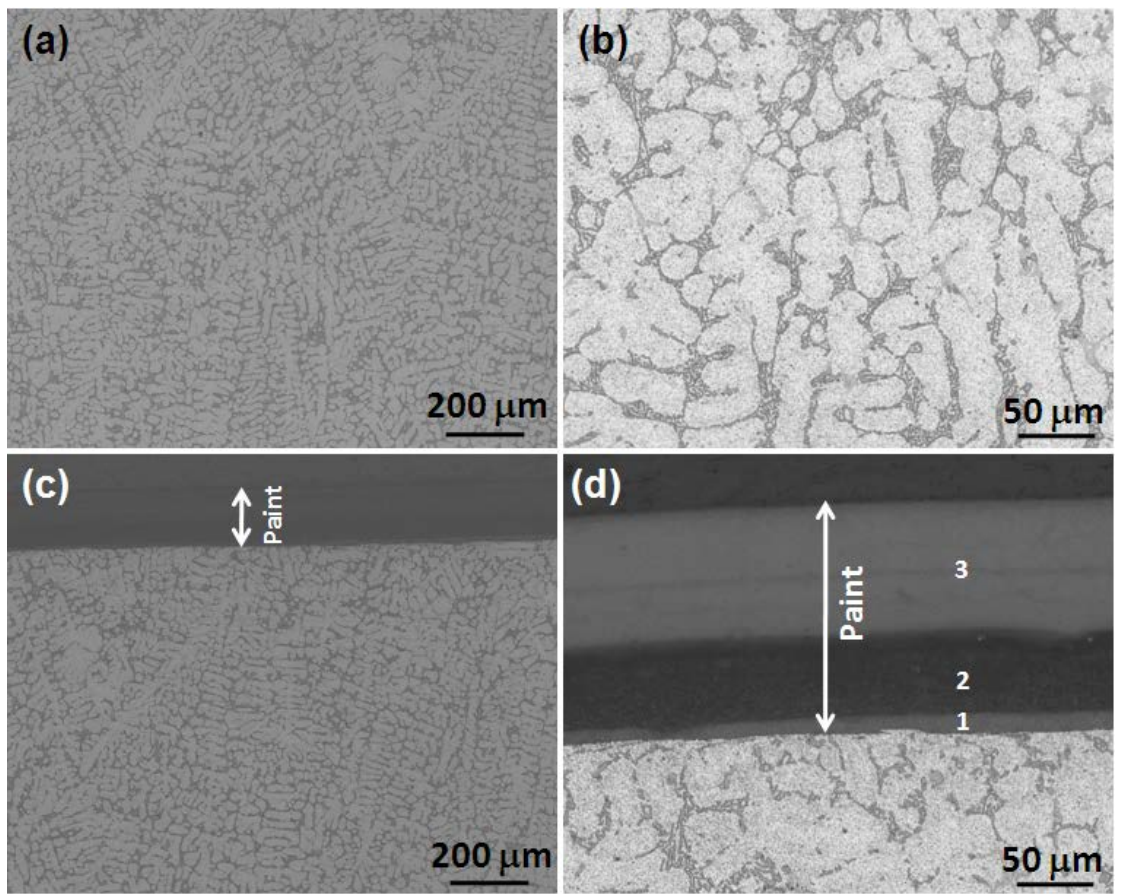

Figure 14: Optical microstructures of the base of the antenna: (a) low and (b) high magnifications; optical microstructure taken from the edge showing different layers of paint: (c) low and (d) high magnifications.
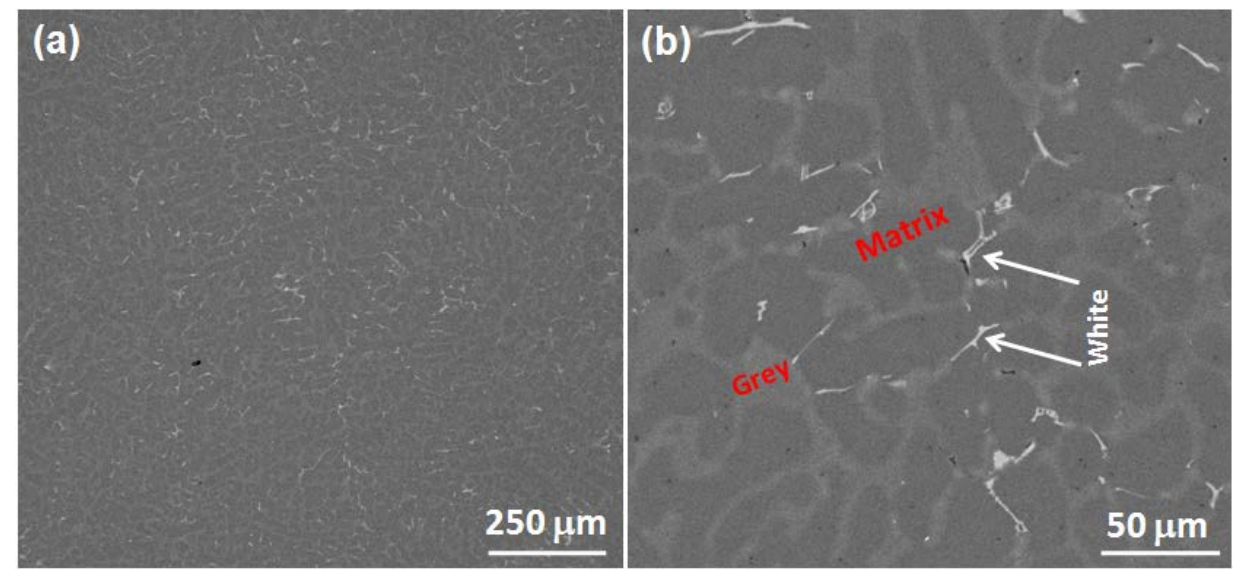

Figure 15: The BSE SEM microstructures of cross section of the base of the antenna: (a) low and (b) high magnifications. 

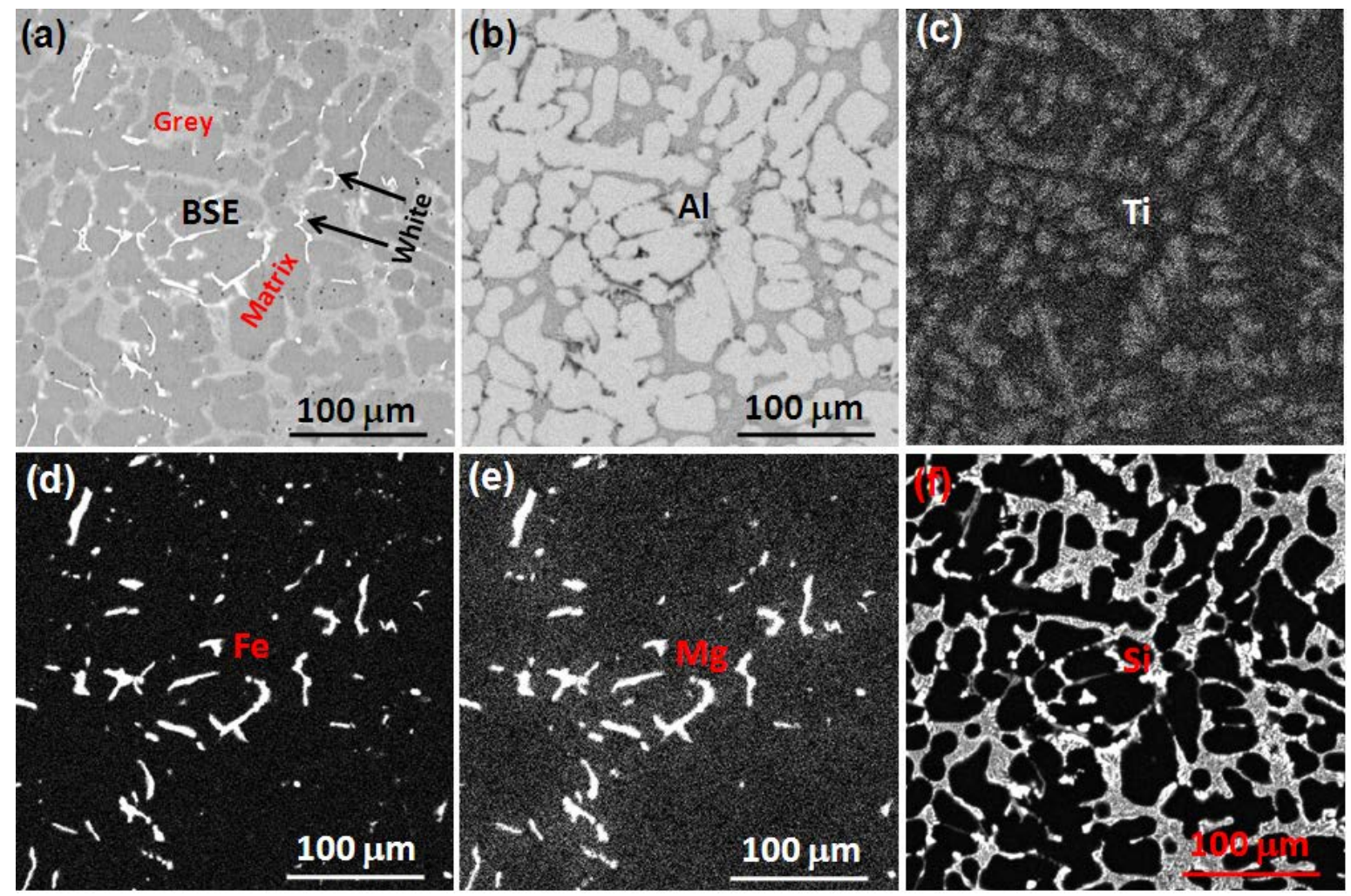

Figure 16: EPMA X-ray elemental mappings of cross section of base of the antenna: (a) BSE image (b) Al, (c) Ti, (d) $\mathrm{Fe},(\mathrm{e}) \mathrm{Mg}$ and (f) Si distributions in corresponding BSE image.
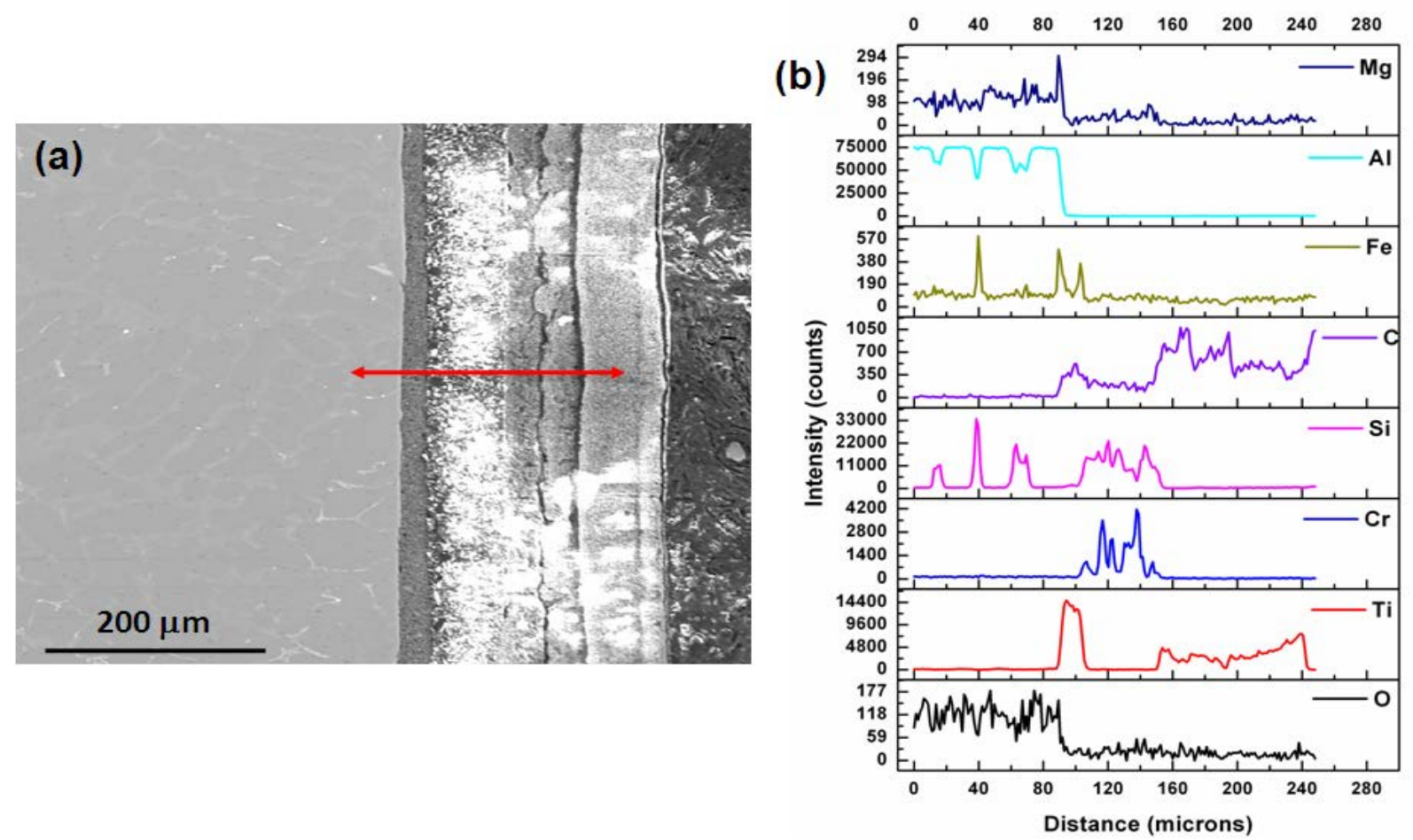

Figure 17: (a) BSE EPMA image taken from the edge consisting of three layers of paint. The region of line scan on paint is shown by double arrow (in red colour) and (b) EPMA elemental line scans taken from the double arrow shown in red colour in Fig. 17a. 
The optical microstructures taken from the edges show the paint layer at the edges (Fig. 14 ( $c$ and d).The paint is shown by double arrows in Fig. 14 ( $c$ and d). The high magnification image (Fig. 14d) exhibits that the paint consists of three layers. These layers are marked as 1, 2 and 3 (Fig. 14d). The thicknesses of layers 1, 2 and 3 are $\sim 25,50$ and $90 \mu \mathrm{m}$, respectively. The microstructures and paint shown in Fig. 14 have been investigated in detail by EPMA. The EPMA elemental line scans of the paint (shown in Fig.14) are exhibited in Fig. 17. As mentioned above, paint consists of three layers (Figs. 14 and 17). The first and third layers display the presence of $\mathrm{Ti}$ and $\mathrm{C}$ while second layer shows the $\mathrm{Si}, \mathrm{Cr}$ and $\mathrm{C}$ elements (Fig. 17b). The small amount of oxygen is also present in all the three layers.

\section{DISCUSSIONS}

The chemical composition determined from the EPMA indicates that the metallic part of antenna is made up of $\mathrm{Al}$ based alloy (Al-Mg-Si). The microstructure exhibits the presence of solidification microstructure indicating that the metallic part of antenna is made in as-cast condition of the material. The as-cast material shows the presence of three phases namely; Al-rich matrix along with Si-rich (grey) and Mg-Si-Fe rich (white) precipitates (Figs. 14 and 15). Similar microstructural features are also reported elsewhere in as-cast Al-Mg-Si alloy [12].

Impact of the object with the antenna has removed paint only. No cracking is observed in the metallic part of the antenna. The $\mathrm{X}$-ray radiograph of the damaged antenna reveals that the presence of severe cracking in middle part of the fin which is made up of a Si based material (Fig. 5). The cracks are appeared in the central region of the fin due to impact of an external object (appears to be blankings and particles in the present case). X-ray radiography observations also show that the fin has been cracked at locations where only Si based material is present inside the fin structure. Cracking observed is highlighted with the white rectangular box (Fig. 5). This can be attributed to hitting of the object at the top of the fin (location C of Fig. 3).

As mentioned above, the paint consists of three layers with different thicknesses. Chemical compositions of the layers 1 and 3 (Fig. 14d) are same while the layer 2 is different. As a result, the contrast of the layers 1 and 3 are nearly same in optical microstructure. Three layers are intact with the metallic part. As mentioned above, the fracture surfaces exhibits two distinctive features: (i) shrinkage casting dendrites along with porosity and (ii) ductile dimples and flat facets. Hossain and Kurny [13] have observed the similar fracture features in as-cast Al-Si-Mg alloy with $\mathrm{Cu}$ contents. Jerner has also reported the similar fracture features in as-cast aluminium alloy [14].

The location A (Fig. 3) exhibits the presence of three types of FOD particles namely small particles and fibres. The small FOD particles ( $\mathbf{a}$ and $\mathbf{b}$ ) display the presence of $\mathrm{O}, \mathrm{Na}, \mathrm{Al}, \mathrm{Cl}$ (Fig. 8) and O, Si elements (Fig. 9). The former and later particles are $\mathrm{Cl}$ and Si rich, respectively. The presence of $\mathrm{Al}$ particularly in particle $\mathrm{a}$ is from the base material. The source of small FOD particles might have come probably from the ground (aircraft parking area) during gale. The SE SEM images (Figs. 10-12) display that these particles are fibres (third type FOD particle). The fibre particles exhibit the presence of $\mathrm{C}, \mathrm{O}, \mathrm{Ca}, \mathrm{S}$ and Fe apart from the base material elements ( $\mathrm{Al}, \mathrm{Mg}$ and $\mathrm{Si}$ ). These fibre particles are undamaged (Fig. 10a), damaged (Fig. 11a) and bent (Fig. 12a). The lengths of fibre particles are different at different regions in location A. However, these fibre particles display two distinct compositions: (i) the particles $c$ and $\mathrm{d}$ mainly consists of $\mathrm{Si}, \mathrm{Ca}, \mathrm{O}, \mathrm{C}$ and $\mathrm{Mg}$. The main source of these particles appears to be large particles lying on the aircraft parking area. These particles might have hit the antenna during gale. (ii) The particle e reflects the presence of $C$ as major element. It appears that the source of this particle is from the aircraft engine blanking material. It has been reported that the aircraft engine blanking material is made up of $C$ fibres. It emerges that all the three types of particles as mentioned above might have hit the antenna during gale. Surprisingly, the location C (Fig. 3) does not show the presence of FOD particles. This can probably be attributed to extent of hitting which is not sufficient to leave any FOD particles at the location C (Fig. 3).

\section{CONCLUSIONS}

Microstructural attributes of failed aircraft antenna in both the un-damaged and impact mark regions have been investigated. The main findings of the results are summarized below.

(a) The antenna appears to be damaged due to hitting of the large particles lying in aircraft parking area and aircraft engine blankings during gale.

(b) Three types of FOD particles are observed on the damaged / hit area. The small FOD particles appear to come from the ground during gale. The large numbers of FOD particles are in the form of fibres.

(c) The source of fibre FOD particles is from aircraft engine blankings material.

\section{ACKNOWLEDGEMENTS}

Authors acknowledge Defence Research and Development Organisation for financial support. We are grateful to Dr Vikas Kumar, Director, Defence Metallurgical Research Laboratory for his kind encouragement. Authors thank members of EMG, SFAG, Photography and Radiography groups of DMRL for their kind help during investigation. 


\section{REFERENCES}

1. Murugan S and Oblah AA.TCAS Functioning and Enhancements, International Journal of Computer Applications (0975-8887) 2010; 1: 45-49.

2. Harman WH, "TCAS: A System for Preventing Midair Collisions", in The Lincoln Laboratory Journal 1989; Volume 2.

3. De D, Chattoraj N, A Review: Theoretical Analysis of TCAS antenna: Traffic Collision Avoidance System for Aircrafts, IEEE International Conference on Green Computing, Communication and Electrical EngineeringICGCCEE'14.

4. M.J. Kochenderfer, Decision making under uncertainty: Theory and approaches, The MIT Press, Cambridge, England 2015.

5. A.L.U. Roberts and S.J. Peimber, Air Traffic Control System, US Patent 9245451, 2016.

6. J. Tang, M.A. Piera, Y. Ling and L. Fan, Extended Traffic Alert Information to Improve TCAS Performance by means of Causal Models, Mathematical Problems in Engineering, Article ID 303768, 2015, 1-11.

7. U.S. Department of Transportation (Federal Aviation Administration); "Introduction to TCAS II", Version 7.1, February 28, 2011.

8. Henely S, TCAS II, Chapter 18, Avionics Handbook, CRC Press LLC, 2001.

9. Kim Wiolland. “Traffic Alert Collision Avoidance System, UNCOVERED”.

10. Welch JD and Orlando VA, Traffic Alert and Collision Avoidance System (TCAS): A Functional overview of minimum TCAS II, Project Report, ATC-119, DOT/FAA/PM-83/10.

11. Boeing Proprietary, Copyright $\odot$ Boeing, Rev 1.0, 3-2.

12. Boromei I, Ceschini L, Morri Al, Morri An, Nicoletto G, Riva E, Influence of the Solidification Microstructure and Porosity on the Fatigue Strength of Al-Si-Mg Casting Alloys, Metallurgical Science and Technology 2010; 28-2: 1824.

13. Hossain A, Kurny ASW, Effects of Strain Rate on Tensile Properties and Fracture Behavior of Al-Si-Mg Cast Alloys with Cu Contents, Materials Science and Metallurgy Engineering 2013: 1: 27-30.

14. Jerner, http://www.metallurgist.com/atvrollover.html. 